\title{
Profile of Vitamin D in Patients Attending at Tertiary Care Hospital, Bangladesh
}

\author{
Salma Sadiya ${ }^{1}$, Md. Masud Rana ${ }^{1,2,3}$, Mashud Parvez ${ }^{1,2,3}$, Mahmuda Monowara ${ }^{1,2,3}$, \\ Afsana Habib Sheuly ${ }^{4}$ \\ ${ }^{1}$ Department of Biochemistry and Molecular Biology, Dhaka Shishu Hospital and Bangladesh Institute of Child Health, Dhaka, Bangladesh \\ ${ }^{2}$ Department of Histopathology, Dhaka Shishu Hospital and Bangladesh Institute of Child Health, Dhaka, Bangladesh \\ ${ }^{3}$ Department of Radiology, Dhaka Shishu Hospital and Bangladesh Institute of Child Health, Dhaka, Bangladesh \\ ${ }^{4}$ Helen Keller International, Dhaka, Bangladesh
}

Email address:

nayeem1997@yahoo.com (S. Sadiya)

\section{To cite this article:}

Salma Sadiya, Md. Masud Rana, Mashud Parvez, Mahmuda Monowara, Afsana Habib Sheuly. Profile of Vitamin D in Patients Attending at Tertiary Care Hospital, Bangladesh. American Journal of Internal Medicine. Vol. 9, No. 2, 2021, pp. 83-86.

doi: 10.11648/j.ajim.20210902.14

Received: February 21, 2021; Accepted: March 17, 2021; Published: March 26, 2021

\begin{abstract}
Introduction: Vitamin D deficiency is a common condition prevalent among both developed and developing countries where it is seen mostly in females. It has been linked to various skeletal and non-skeletal diseases. This study was done to find out the distribution of Vitamin D deficiency attending the outpatient department of a tertiary care hospital. Methods: This descriptive cross-sectional study was done among the patients attending the outpatient department of a tertiary care hospital in Dhaka, Bangladesh. Methodology: The six months study was conducted from January 2019 to July 2019. The ethical approval was taken from the Institutional Review Committee of the institute where we conducted the study. Convenient sampling was done. The collected data was entered in Microsoft Excel and was analyzed in the Statistical Package for the Social Sciences (SPSS) version 23. Results: Out of 170 participants, the distribution of vitamin D deficiency was $24(14.1 \%)$ and insufficient vitamin D in $59(34.7 \%)$ of the patients. The mean serum vitamin D concentration by gender was $33.20 \pm 13.10 \mathrm{ng} / \mathrm{ml}$ in males and $29.85 \pm 9.99 \mathrm{ng} / \mathrm{ml}$ in females. Mean age of deficient cases are $18.25 \pm 23.47$ years and for sufficient cases mean age is $6.92 \pm 7.36$ years. A total of 16 females and 8 males had vitamin D deficiency. Conclusions: Vitamin D deficiency was prevalent especially in girl child.
\end{abstract}

Keywords: Vitamin D, Deficiency, Children, Bangladesh

\section{Introduction}

Vitamin D is a fat-soluble prohormone, the main activity of this is the regulation of the physiological processes [1]. It is found in two forms; from plants and fungi as ergocalciferol (Vitamin D2), and from the sun as cholecalciferol (Vitamin D3) [2]. "25- hydroxyvitamin D level of less than 20ng per millimeter (50nmol per liter)" is defined as Vitamin D deficiency $[3,4]$.

Globally it has been estimated that around one billion people is suffering from Vitamin D deficiency or insufficiency [5]. Vitamin D deficiency is found high in the developed countries and the regions of Asia, the Middle East, and India mostly in women [6]. According to several studies,
$40-100 \%$ of the US and European population are deficient in Vitamin D [7, 8]. The factors behind this Vitamin D deficiency could be due to changes in the lifestyle of modern era based on the socio-cultural norms and practices, inadequate sun exposure and the food consumed that are rarely fortified with Vitamin D [9].

The consequence of the Vitamin D deficiency may associated with rickets in children and osteomalacia and osteoporosis in adults. Its association with various cardiovascular, infectious (tuberculosis), and cancers has been recently reported [10]. Thus, Vitamin D deficiency is related only with skeletal but also with extraskeletal diseases including neuromuscular, endocrinal, cardiovascular, degenerative, and autoimmune diseases [11]. It is known that 
exposure to ultraviolet B rays helps to Vitamin D is synthesiz Vitamin D in the skin. So sun exposure is very important. Vitamin D deficiency is multi-factorial in origin, and some of the risk factors are poor sunlight exposure, skin pigmentation, and dietary insufficiency. Atmospheric pollution has also been endorsed to Vitamin D deficiency in children [12].

Cultural and social practices including lifestyle pattern such as covering of body part with clothing (Burkha or veil including black socks covering hand and feet) that limit the exposure to sunlight impact the level of Vitamin D in the body.

Vitamin D is very vital for human body. It is not just a vitamin, but actually a hormone, thus a class by itself and its predominant renal metabolic product, calcitriol, a secosteroid hormone, targets over 1000 genes in the human body. Role of Vitamin D deficiency has been associated as factor responsible in the pathogenesis of 17 varieties of cancers, heart disease, stroke, hypertension, autoimmune diseases, diabetes, depression, chronic pain, osteoarthritis, osteoporosis, myopathies, birth defect, dental diseases, and many more diseases [13].

Professor Michael Hollick who did research on Vitamin D has argued that a few minutes in the summer sun produces 100 times more Vitamin D than daily requirement [14]. Sufficient serum level of vitamin D is crucial to maintain the autocrine and paracrine functions. Otherwise low Vitamin D results in oncogenesis and affects the basic cell biology [13].

In the current world Vitamin D deficiency is a burden which is documented by many recent studies Moderate-tosevere Vitamin D deficiency is reported in urban Indian population, despite availability of abundant sunshine [15-17]. Furthermore, the high prevalence of clinical and biological hypovitaminosis D in apparently healthy school children has been reported in India [18]. Thorough and close clinical examination during school time is necessary to identify accurate Vitamin D deficiency in school children [15]. Because of asymptomatic nature of symptoms of Vitamin D deficiency, it remains undetected in a majority of individuals [15]. Clinical detection of symptomatic cases is the tip of iceberg of Vitamin D deficiency. Myth of routine exposure to sunshine does not require extra Vitamin D, results in severe asymptomatic Vitamin D deficiency in Indian population.

The objective of this study is to see the distribution of vitamin D level among children as well as adult at a tertiary care hospital in Bangladesh.

\section{Methodology}

This descriptive cross-sectional study was done among patients attending the outpatient department (OPD) of a tertiary Care hospital in Dhaka, Bangladesh The study was conducted from January 2019 to July 2019. The ethical approval was taken from the Institutional Review Committee of the Hospital. Consecutive patients attending outpatient department (OPD) were invited to participate in this study. Patients from all age group, religion, gender, and occupation who attended OPD were eligible to participate. Written informed consent was obtained, and then participants were subjected to clinical and laboratory investigations. For children consent was taken from guardian.

We have collected information on age, gender, and prevailing symptoms and known medical disorders such as diabetes, hypertension, and IHDs. We have also probed for symptoms such as weakness, laziness, muscle aches, and bony pain. Then, general and systemic clinical examination was done on every patient. After obtaining written consent, 3 $\mathrm{ml}$ of blood sample was collected by phlebotomy in dry glass test tube and was transferred in cool-box to the laboratory. The term "Vitamin D" refers to compound Vitamin D3 (cholecalciferol) or Vitamin D2 (ergocalciferol). Vitamin D3 level in serum was estimated by electro-chemiluminescence on cobas elecsys 411 fully automated system.

Vitamin D deficiency was defined as $25(\mathrm{OH})$ D less than 20ng/ml, Vitamin D insufficiency as $20-<30 \mathrm{ng} / \mathrm{ml}$, and Vitamin D sufficiency as 30-100 $\mathrm{ng} / \mathrm{ml}$, and Vitamin D toxicity as more than $100 \mathrm{ng} / \mathrm{ml}$. Vitamin D levels less than $10 \mathrm{ng} / \mathrm{ml}$ were regarded as a severe deficiency. ${ }^{2}$

\section{Results}

In the current study total 170 respondents took participation, the age range was from 4 months to 84 years. Among them 156 were below age 18 years. The demographic details are given in table 1 .

Table 1. Demographic and clinical characteristics of respondents $(n=170)$.

\begin{tabular}{lll}
\hline characteristics & Number & percentage \\
\hline Gender & & \\
Male & 82 & 48.2 \\
Female & 88 & 51.8 \\
Age & & \\
Median & 6 years & \\
Minimum & 4 month & \\
Maximum & 84 years & \\
S. Vit D (ng/ml) & & \\
Mean \pm SD & $31.46 \pm 11.67$ & \\
Minimum & 8.25 & \\
Maximum & 97.40 & \\
\hline
\end{tabular}

Age and gender are two important variables for any diagnosis and distribution pattern of any vitamin and minerals. The distribution of S Vitamin D according to age and gender is given in table 2. It is found that among male, Vitamin D distribution is more than female.

Table 2. Distribution of S. Vitamin D according to gender and age $(n=170)$.

\begin{tabular}{lllll}
\hline Variables & Mean & SD & Minimum & Maximum \\
\hline Gender & & & & \\
Male & 33.20 & 13.16 & 13.10 & 97.46 \\
Female & 29.85 & 9.99 & 8.25 & 94.43 \\
Age & & & & \\
$<18$ years & 32.20 & 11.80 & 8.25 & 94.74 \\
18 years and more & 26.49 & 9.60 & 13.92 & 46.63 \\
\hline
\end{tabular}

Serum Vitamin D status is categorized into four groups according to serum level. Deficiency, insufficiency, sufficiency and toxic. In our study, no case of toxic is found. Other categories details are given in Table 3. 
Table 3. Distribution of $S$ vitamin D status among the respondents $(n=170)$.

\begin{tabular}{lll}
\hline Status of Vitamin D $(\mathbf{n g} / \mathbf{m l})$ & Number & percentage \\
\hline Deficiency & 24 & 14.1 \\
Insufficiency & 59 & 34.7 \\
Sufficiency & 87 & 51.2 \\
\hline
\end{tabular}

The details of s. Vitamin D status according to categories and age and gender is given in table 4 .

Table 4. Distribution of S. Vitamin D according to age and gender.

\begin{tabular}{llll}
\hline Variables & $\begin{array}{l}\text { Deficiency } \\
(\mathbf{n = 2 4 )}\end{array}$ & $\begin{array}{l}\text { Insufficiency } \\
(\mathbf{n = 5 9 )}\end{array}$ & $\begin{array}{l}\text { Sufficient } \\
(\mathbf{n = 8 7})\end{array}$ \\
\hline $\begin{array}{l}\text { S. Vitamin D } \\
(\mathrm{n} / \mathrm{ml})\end{array}$ & & \\
$\begin{array}{l}\text { Mean } \pm \text { SD } \\
\text { Minimum }\end{array}$ & $15.37 \pm 3.31$ & $25.43 \pm 2.87$ & $40.0 \pm 9.40$ \\
Maximum & 8.25 & 20.00 & 30.0 \\
Age & 19.74 & 29.86 & 97.4 \\
Mean \pm SD & $18.25 \pm 23.47$ & $11.69 \pm 6.7$ & $6.92 \pm 7.36$ \\
Minimum & 6 months & 4 months & 4 months \\
Maximum & 84 years & 68 years & 46 years \\
Gender & & & \\
Male & $8(33.3)$ & $32(54.2)$ & $42(48.3)$ \\
Female & $16(66.7)$ & $27(45.8)$ & $45(51.7)$ \\
\hline
\end{tabular}

\section{Discussion}

The results of this cross-sectional study done in a tertiary care hospital of Dhaka, Bangladesh showed the prevalence of Vitamin D deficiency as $14.1 \%$, of insufficiency as $34.7 \%$, and sufficient Vitamin D in $51.2 \%$. The prevalence was higher among older ages and females. A severe deficiency was seen in $14.1 \%$ of the studied population. The rates of Vitamin D deficiency found in this study are markedly higher than in many western countries like in Germany, Austria, and the Netherlands, in North Europe (Denmark, Finland, Ireland, and Poland), Canada, and the United Kingdom where the prevalence of vitamin D deficiency ranges from 10-55.5\% $[19,20]$.

Mariam Omar et al. from Libya reported a deficiency of $76.1 \%$ and insufficiency of $15.2 \%$ among the population of Benghazi, a sunny city in the east of the country [2]. Our results share similar vitamin D deficiency status with some parts of Africa, Asia, and the Middle East. The prevalence of vitamin D deficiency in Egypt was $77 \%$, insufficiency was $15 \%$, and $9 \%$ of the population has sufficient Vitamin D levels. In Qatar, it is estimated that $83-91 \%$ of the population is deficient in Vitamin D [2, 21].

Vitamin D deficiency is considered to be a public health problem worldwide. Female gender is one of the most important predictors of vitamin D deficiency globally [2]. In this study, $48.2 \%$ of the participants were males and $51.8 \%$ were females. Among the deficiency category $66.7 \%$ were female which is alarming and correspondence with findings from other countries [2]. Babita Ghai et al. reported $73 \%$ of the female to be vitamin D deficient [14]. In contrast, Manoharan et al. studied the vitamin D status among people of Tamil Nadu, India, reported that $46 \%$ of the males and $37 \%$ of the females had a vitamin D deficiency [22].

The mean age of deficiency category was $15.37 \pm 23.47$ years and mean age for insufficiency was $11.69 \pm 11.67$ years. Various studies report a similar observation by demonstrating lower vitamin D levels with increasing ages and higher vitamin D deficiency states in the older age group, mandating early investigating and thus helping them to prevent falls and fractures $[2,23]$.

Our study has demonstrated a high prevalence of vitamin $\mathrm{D}$ deficiency among patients visiting in our center. A larger multicentric or community based study with a diverse sample population should be conducted in the future to find out a more accurate prevalence. Similarly, other studies that further look into the association between gender and age and other comorbidities with vitamin D levels in Bangladeshi are warranted.

\section{Conclusion}

Vitamin D was found sufficient among half of the study population and half was found with insufficient or deficient. Among them Vitamin D deficiency was prevalent especially in girl child compare to boy. Thus, physicians should be vigilant to rule out Vitamin D deficiency and consider supplementation in those who are at risk.

\section{References}

[1] Kheiri B, Abdalla A, Osman M, Ahmed S, Hassan M, Bachuwa G. Correction to: Vitamin D deficiency and risk of cardiovascular diseases: a narrative review. Clin Hypertens. 2018 Dec 24; 24: 19.

[2] Omar M, Nouh F, Younis M, Younis M, Nabil N, Saad M, et al. Vitamin D Status and contributing factors in patients attending three polyclinics in Benghazi Libya. Journal of Advances in Medicine and Medical Research. 2017 Nov 6; 24 (5): 1-13.

[3] Holick MF. High prevalence of vitamin D inadequacy and implications for health. Mayo Clin Proc. 2006 Mar; 81 (3): 353-73.

[4] Malabanan A, Veronikis IE, Holick MF. Redefining vitamin D insufficiency. Lancet. 1998 Mar 14; 351 (9105): 805-6.

[5] Holick MF, Siris ES, Binkley N, et al. Prevalence of Vitamin D inadequacy among postmenopausal North American women receiving osteoporosis therapy. J Clin Endocrinol Metab. 2005 Jun; 90 (6): 3215-24.

[6] Bischoff-Ferrari HA, Giovannucci E, Willett WC, et al. Estimation of optimal serum concentrations of 25hydroxyvitamin D for multiple health outcomes. Am J Clin Nutr. 2006 Jul; 84 (1): 18-28.

[7] Glerup H, Mikkelsen K, Poulson L, et al. Community recommended daily intake of Vitamin D is not sufficient if sunlight exposure is limited. J Intern Med. 2000 Feb; 247 (2): 260-8.

[8] Lips P, Hosking D, Lippuner K, Norquist J M et al. The prevalence of vitamin D inadequacy amongst women with osteoporosis: an international epidemiological investigation. J Intern Med. 2006 Sep; 260 (3): 245-54. 
[9] Bouillon R, Van Schoor NM, Gielen E, Boonen S, Mathieu C, Vanderschueren D, et al. Optimal vitamin D status: a critical analysis on the basis of evidence-based medicine. J Clin Endocrinol Metab. 2013 Aug; 98 (8): E1283-304.

[10] Trilok Kumar G, Chugh R, Eggersdorfer M. Poor Vitamin D status in healthy populations in India: A review of current evidence. Int J Vitam Nutr Res. 2015; 85: 185-201.

[11] Ritu G, Gupta A. Vitamin D deficiency in India: Prevalence, causalities and interventions. Nutrients. 2014; 6: 729-75.

[12] Agarwal KS, Mughal MZ, Upadhyay P, Berry JL, Mawer EB, Puliyel JM. The impact of atmospheric pollution on Vitamin D status of infants and toddlers in Delhi, India. Arch Dis Child. 2002; 87: 111-3.

[13] Pludowski P, Holick MF, Pilz S, Wagner CL, Hollis BW, Grant WB, et al. Vitamin D effects on musculoskeletal health, immunity, autoimmunity, cardiovascular disease, cancer, fertility, pregnancy, dementia and mortality-a review of recent evidence. Autoimmun Rev. 2013; 12: 976-89.

[14] Holick MF. Calcium and Vitamin D. Diagnostics and therapeutics. Clin Lab Med. 2000; 20: 569-90.

[15] Goswami R, Gupta N, Goswami D, Marwaha RK, Tandon N, Kochupillai N. Prevalence and significance of low 25hydroxyvitamin D concentrations in healthy subjects in Delhi. Am J Clin Nutr. 2000; 72: 472-5.

[16] Marwaha RK, Tandon N, Garg MK, Kanwar R, Narang A, Sastry A, et al. Vitamin D status in healthy Indians aged 50 years and above. J Assoc Physicians India. 2011; 59: 706-9.
[17] Arya V, Bhambri R, Godbole MM, Mithal A. Vitamin D status and its relationship with bone mineral density in healthy Asian Indians. Osteoporos Int. 2004; 15: 56-61.

[18] Marwaha RK, Sripathy G. Vitamin D \& bone mineral density of healthy school children in northern India. Indian J Med Res. 2008; 127: 239-44.

[19] G R, Gupta A. Vitamin D deficiency in India: prevalence, causalities and interventions. Nutrients. 2014 Feb 21; 6 (2): 729-75.

[20] Russ TC, Murianni L, Icaza G, Slachevsky A, Starr JM. Geographical Variation in Dementia Mortality in Italy, New Zealand, and Chile: The Impact of Latitude, Vitamin D, and Air Pollution. Dement Geriatr Cogn Disord. 2016; 42 (1-2): $31-41$.

[21] Badawi A, Arora P, Sadoun E, Al-Thani AA, Al Thani MH. Prevalence of vitamin D insufficiency in Qatar: A systematic review. J Public Health Res. 2012 Dec 28; 1 (3): 229-35.

[22] Manoharan A, Selvaraj P, Vasanthamani P. Vitamin D level among patients with nonspecific musculoskeltal pain attending tertiary care hospital in Tamil Nadu. International Journal of Orthopaedics Sciences. 2016: 2 (4): 94-96.

[23] Hilger J, Friedel A, Herr R, Rausch T, Roos F, Wahl DA, et al. A systematic review of vitamin $\mathrm{D}$ status in populations worldwide. Br J Nutr. 2014 Jan 14; 111 (1): 23-45. 